\title{
Conduite des troupeaux et organisation du territoire pâturé en région méditerranéenne
}

\author{
B Hubert 1, S Bellon 1, J Lasseur 1, B Leclerc ${ }^{1}$, E Lécrivain ${ }^{1}$, \\ M Meuret 1, G Molénat 2, M Napoléone 1, M Prud'hon 2 \\ 1 INRA-SAD, Écodéveloppement, BP 91, 84143 Montfavet Cedex; \\ 2 INRA-ENSA M, UZM, place Viala, 34060 Montpellier, France
}

La région méditerranéenne française se caractérise par une grande diversité de systèmes d'élevage, valorisant une large gamme de situations géographiques et écologiques. De nombreux systèmes sont fondés sur le pâturage de différents types d'espace, sur lesquels des communautés végétales très diverses contribuent aux ressources prélevées par les troupeaux. Ces élevages méditerranéens reposent ainsi traditionnellement sur des modèles de production relativement extensifs, au sens d'une large utilisation de leur territoire pâturé. II paraît alors intéressant d'en tirer quelques enseignements généralisables.

Cet article montre comment des éleveurs organisent le pâturage sur un territoire diversifié, en conduisant le troupeau en fonction de leurs objectifs de production. Nous observons les pratiques et enregistrons en même temps les productions, dans des exploitations choisies d'après leur mode de fonctionnement. Une modélisation conjointe des processus de production et des prises de décision de l'éleveur nous permet de rendre compte à la fois des performances et des processus qui les ont générés. Nous identifions ainsi des “modèles d'action» des éleveurs et cela nous permet d'émettre un diagnostic sur l'efficacité de leurs pratiques, qui soit pertinent par rapport aux finalités qui leur sont attribuées par les éleveurs. Cette démarche peut être appliquée à l'échelle de la campagne annuelle aussi bien qu'à celle d'un circuit de pâturage.

II apparaît ainsi que ces pratiques complexes d'alimentation ne peuvent être ramenées à la seule confrontation classique entre demande alimentaire et offre fourragère. En effet, nous montrons que :

- la gestion, sur une campagne, met en œuvre un ensemble de processus biologiques (comme l'évolution des réserves corporelles ou la dynamique d'une végétation soumise à différents rythmes de pâturage), ainsi que différentes décisions (d'allotement, d'utilisation conjointe de couverts végétaux distincts, etc) dans une organisation qui associe des objectifs directement productifs à d'autres d'ordre sécuritaire;

- la valeur d'une surface pastorale résulte autant de sa nature (composition botanique) que de sa localisation dans l'espace (éloignement de la bergerie, proximité de ressources complémentaires), du moment où elle sera visitée (en début ou en fin de repas), et de la manière dont le troupeau y est mené (horaire, vitesse de déplacement, étalement du groupe, équipements et structure du pâturage, etc). 